\title{
Attitudes and Preferences of Advanced Learners Towards Siraiki Dictionaries
}

\author{
Muhammad Tariq Ayoub ${ }^{1} \&$ Zafar Iqbal $^{1}$ \\ ${ }^{1}$ Department of English, Bahauddin Zakariya University, Multan, Pakistan \\ Correspondence: Hafiz Muhammad Qasim, Assistant professor, GC University, Faisalabad, Pakistan. E-mail: \\ m_qasim@hotmail.com
}

Received: October 5, 2019 Accepted: October 27, 2019 Online Published: December 14, 2019

doi:10.5539/ijel.v10n1p47 URL: https://doi.org/10.5539/ijel.v10n1p47

\begin{abstract}
This study investigates the attitudes and preferences of advanced learners of the Siraiki language towards Siraiki dictionaries available in Pakistan. Descriptive in nature, the study is quantitative approach and has employed survey questionnaire as tool of data collection. The main objectives of the study are: a) to identify the attitudes of advanced learners of the Siraiki language towards using a dictionary for learning a language, $b$ ) to identify the types of dictionaries that advanced learners of the Siraiki language prefer most and c) to identify the preferences of advanced learners of the Siraiki language towards their dictionaries and to identify their hurdles and problems towards dictionary use. The subjects of this study comprised 230 advanced learners of Siraiki (138 male and 92 female) from 18 to 24 years of age. The number of respondents at graduate level was 212 and 18 at masters' level respectively. The subjects of the study were selected through purposive sampling technique. This study reported that 58 out of 230 respondents owned dictionaries. Majority of the respondents reported that dictionary use was a time-consuming task. Siraiki dictionaries were found deficient in organizing lexemes in canonical form, provision of collocations and definitions. Most of the respondents used dictionaries for meaning, followed by pronunciation, spelling, grammar, examples and notes on usage notes respectively. All the students were willing on getting training on dictionary use.
\end{abstract}

Keywords: dictionary use, advanced learners, attitudes and preferences towards dictionaries

\section{Introduction}

\subsection{Background of the Study}

Dictionary as a reference work containing words organized and arranged alphabetically, provides information on word forms, pronunciations, functions, meanings, etymologies, spellings and idiomatic uses. Hartmann (1983) believes it to be a 'reference book or list of words (usually in alphabetical order) in other languages'. Zgusta (1971) defines dictionary as 'a systematically arranged list of socialized linguistic forms compiled from the speech habits of a given speech community and commented upon in such a way that the qualified reader understands the meaning of each separate form, and is informed of the relevant facts concerning the function of that form in its community'.

The significant role played by a good dictionary in language learning is sadly underestimated in Pakistan due to lack of understanding on the part of dictionary users (Haseeb, 2007). Learners have reportedly been found to be lacking in tendency to use a dictionary for enhancing their knowledge about the language. Even the well-educated dictionary users generally exhibit faulty habits in dictionary use like they usually look up only the meaning of words. The learners of the Siraiki language are in no way exception to such dictionary using habits and the most obvious reason is lack of training in the use of dictionaries. They are not properly tutored and guided as to how to exploit full potential of dictionaries for learning pronunciation, grammatical categories and other entries presented in the micro-structure of a dictionary. Cowie (1999) opines that successful use of a dictionary calls for a specific competence, and many students do not possess it due to appropriate training. Dictionary no doubt continues to be seen positively as an instrument designed with a view to providing quick help and support in case of emergency regarding proficiency in language learning (Béjoint, 1999). In this study, we wanted to investigate the habits, attitudes and preferences of advanced learners of the Siraiki language in Pakistan so that a coherent view on dictionary use among Siraiki learners may be formulated. 


\subsection{Purpose of the Study}

Dictionary users do not get the best out of their dictionaries in the absence of appropriate dictionary reference skills. Advanced learners of the Siraiki language have on one hand little tendency towards using dictionaries and exploiting the full linguistic knowledge dictionaries provide on the second hand. Tono (2001) believes that user of a language has a very limited understanding of dictionary conventions and some of the users are even not cognizant with the distinction between 'transitive vs. intransitive verb, to say nothing of countable vs. uncountable nouns'. The learners happen to be lacking in formal training in the use of dictionary. They have very limited understanding of the dictionary and the wealth of information it offers.

\subsection{Objectives of the Study}

The present study aimed to investigate:

1) To identify the attitudes of learners of Siraiki at advanced level towards using a dictionary in language learning.

2) To explore the kind of dictionaries learners of Siraiki at advanced level prefer most.

3) To identify the preferences of learners of Siraiki at advanced level towards their dictionaries and identify their hurdles and problems towards dictionary use.

\subsection{Research Questions}

The study investigates the following questions:

1) For what specific purposes do learners of Siraiki at advanced level consult a dictionary?

2) What lexical knowledge do they look-up most?

3) What problems do Siraiki learners at advanced level encounter while consulting dictionary?

4) How can adequate training in dictionary use help them improve their reference skills?

\subsection{Significance of the Study}

The study is significant in the following ways:

1) The study will provide detailed information on the dictionary using habits of advanced learners of the Siraiki language. It will also highlight their needs and problems in using dictionaries. It will be a pioneering research on dictionary using habits of advanced learners of the Siraiki language in Pakistani setting.

2) The study will highlight the causes, hurdles and hindrances which do not let the learners of the Siraiki language use dictionaries properly.

3) Findings of this research will be very helpful for the compilers of the Siraiki dictionaries and for the linguists who want to know the habits of advanced learners of the Siraiki language in this part of the country.

\section{Review of Related Literature}

Tang (1997) conducted her study on 254 Chinese ESL students of English and 20 ESL teachers at Vancouver, Canada. She aimed at examining the students' use of the HHE (Hand-Held Electronic) dictionary as a tool for learning English and its strengths and weaknesses as perceived by ESL teachers. She found that a very high number $(87 \%)$ of the respondents possessed HHE dictionaries. Students considered their dictionaries beneficial because of their availability, easy access, and convince in carrying.

Momoi (1998) carried out the study on dictionary use in the context of L2 writing (L2/L1 translation) employing thinking-aloud protocols. The findings of the study confirm the view that the bilingual users make use of translation equivalents as well as illustrations without paying little attention to such information as usage notes, cultural notes and contrastive features of two languages namely English and Japanese.

Li (1998) explored the ownership and the frequency of dictionary use among Chinese ESP students as a part of her research to investigate how 801 teachers and students at a Chinese university of science and technology used their dictionaries in their work and studies. She found that $96.8 \%$ of the respondents owned English-Chinese dictionaries, $45.3 \%$ owned Chinese-English dictionaries, 32.3\% owned special-purpose dictionaries and 27.7\% owned monolingual dictionaries. Her study revealed that: (a) the users preferred to use a bilingual dictionary more frequently than monolingual or bilingualised ones, (b) some of her participants followed their teacher's advice in choosing to buy a dictionary, (c) all of her students owned at least one dictionary, with about one third owning a combination of monolingual English and bilingualised English-Chinese dictionaries, and another one third owning these two and an electronic dictionary, and (d) her participants were confident when using the 
alphabetical system in order to locate the headwords. (She observed them while doing a translation test and discovered that most of the students could locate headwords by means of guide words at the top of the pages and the thumb index.)

Hartmann (1999) carried out a study on dictionary use among graduates at the University of Exeter. He administered a questionnaire on 2,040 students from fields of Business and Economics, Education, Engineering and Computer Science, English and Modern Languages and two centers namely Foreign Language Centre and English Language Centre. The responses thus gathered helped him frame opinions regarding (a) the difficulties learners faced while dictionary use and (b) the possible causes behind their failure in dictionary use.

Nesi (1999) investigated dictionary-using habits at the Warwick University. The respondents being ten in number were reported to be keener on portable instead of print dictionary. Despite of availability of print dictionaries, they preferred HHE dictionaries because of certain advantages which are particularly electronic or digital gadgets like database, connectivity with other appliances, portability and typing/editing options.

Tono (2001) explored the effect of dictionary use while leading comprehension in EFL context in Japan. He conducted and completed his research in series of investigations among the Japanese learners of English. Nesi and Hail (2002) investigated dictionary use in EFL context. The respondents in the study comprised of international students using English as medium of instruction at the University of Warwick. Campoy-Cubillo (2002) conducted a study on the dictionary use and needs in ESP context. The subjects in this study belong to subject of Chemistry.

Papanikolaou (2003) conducted a study on students' difficulties with dictionary use in Greek. The subjects of her study were Greek students at secondary level. She found that her subjects experienced failure to find the appropriate entry in the dictionary, especially with multiword items. Papanikolaou (2003) described in her study that her students encountered difficulties with their dictionary, such as, (a) failure to recognize that the word is inflected, (b) long entries, and (c) failure to understand the L1 concept. Marjeta (2004) carried out a study in the context of EFL lexicography in Slovenia. Lew (2004) sought to explore the dictionary use while encoding in Poland. The study explored the relative significance of the monolingual, bilingual or bilingualised dictionaries for learners of English in Poland. The study revealed that monolingual dictionaries are less preferred among the polish students. Chan (2004) investigated the use of the dictionary among 16 Chinese high school students. She found that her participants consulted the bilingualised dictionary more than the bilingual and the monolingual dictionary.

Wingate (2004) conducted a study on difficulties with dictionary use. She found that failure in identifying the unknown word in the dictionary was a common problem amongst the subjects. She found that the students encountered problems: i) in looking up compound nouns ii) idiomatic phrases and iii) citation forms of the past participle. She found out that the problem was caused due to the fact that the learners attempted to look up the compounds as a whole and thus failed to locate the appropriate entry.

Ramos (2005) investigated dictionary use among Spanish students. She found that the major dictionary use problem encountered by her Spanish university students was their lack of ability to find the words they were looking for. Of the students, $32.7 \%$ also stated that it was difficult for them to find the specific information they needed in their dictionaries. Additionally, about $26.5 \%$ of the students were unable to understand the definitions. She noted that students related their difficulties with their dictionary. Nearly $45.9 \%$ of the students claimed that they faced these problems because of the dictionary they possessed and very few considered these problems were attributed to other factors such as their lack of familiarity with the dictionary such as: a) lack of dictionary skills b) unclear layout of the dictionary. In case of idiomatic Phrases, the respondents of the study failed to identify them on two reasons: i) they look up the entry partially and ii) they were not aware whether their dictionary provides idioms or not.

Ryu (2006) conducted a study about dictionary use by EFL students at a university in Korea. The study reported that a large number of the participants (90\%) possessed at least one English paper dictionary. $27 \%$ of the respondents possessed two dictionaries and $12.7 \%$ of the respondents possessed three dictionaries. Only one participant possessed more than three dictionaries. Monolingual dictionaries were possessed by 57 participants; more than two monolingual dictionaries were possessed by 04 participants. Bilingual dictionaries were possessed by the majority of the students. $38.6 \%$ of the respondents possessed Hand-held electronic (HHE) dictionaries. Kobayashi (2006) conducted a study on the use of HHE dictionaries as compared to printed dictionaries by Japanese learners of English at university level in Japan. The study reported that a large number of respondents (72\%) possessed an HHE dictionary. 
Ashraf (2010) conducted a survey to examine dictionary use of the learners of Urdu at advanced level and their attitudes towards dictionary in Pakistan. She selected 400 students (169 males and 231 females) and 87 teachers of the Urdu language. Questionnaire was employed for the collection of data. The study reported that the subjects were well aware about the concept of dictionary and its use. A large number of respondents reported that at Intermediate level, they used dictionaries more than at Secondary level. Findings of the study revealed the fact that the respondents used dictionaries for meaning, pronunciation, grammatical information and the usage of the words and the same were informed by Urdu teachers. The subjects showed dissatisfaction with the dictionaries concerning definition. The teachers of the Urdu language believed that learners of the Urdu language should be motivated towards dictionary use while learning the Urdu language. Teachers were found dissatisfied with current dictionaries.

Sibtain (2011) carried out a research on the structure and the use of the dictionaries of the Punjabi language in Pakistan. His study aimed at describing an overall assessment of Punjabi dictionaries with reference to: (a) their design features, (b) attitudes of their users, (c) prospects of developing them into more user-friendly dictionaries, and (d) the need of developing a corpus for compilation of better dictionaries. The study is descriptive by nature. Both qualitative and quantitative approaches were used. The data were collected through a questionnaire and semi-structured interviews. He selected 403 (258 males and 145 females) Punjabi-speaking students as the subjects of his study. Regarding the attitudes of the learners towards dictionaries, the study reported: 188 (46.65\%) respondents owned bilingual dictionary and $35(8.68 \%)$ respondents owned monolingual dictionary. $163(40.44 \%)$ respondents found dictionaries useful in leaning Punjabi. 213 (52.85\%) subjects were of the opinion that dictionaries provided the meaning they looked up. About inclusion of the information in the monolingual dictionary, the study reported: alphabetic order $205(50.86 \%)$, entries in canonical order $36(8.93 \%)$, senses 66 (16.37\%), collocation $05(1.24 \%)$, spelling $190(47.14 \%)$, definitions 148 (36.72\%), grammar 302 (74.93\%); and examples 101 (25.6\%). 299 (74.19\%) respondents were of the opinion that a lot of time is consumed while using dictionaries. It was found that Punjabi dictionaries were deficient as for as macro- and micro-structures of dictionaries were concerned. Punjabi dictionaries were used by the respondents for production purposes.

Al-harbi (2012) conducted a study to investigate empirically the impacts of dictionary strategy instruction and exposure on the dictionary performance, perceptions and attitudes towards dictionary use, and knowledge of dictionary strategy and use by tertiary students of English in Saudi Arabia. The study was conducted in two phases. Interview, questionnaire, observation and participants' feedbacks were employed for the collection of data. The study reported that: $97.4 \%$ of the participants owned at least one dictionary. $49.3 \%$ owned bilingualised English-English-Arabic dictionary, 44\% bilingual English-Arabic dictionary, 5.3\% bilingual Arabic-English dictionary, 1.3\% monolingual English dictionary. About the inclusion of information in the dictionary, the participants reported that: alphabetical order $(94.6 \%)$, pronunciation $(71.6 \%)$, grammatical information $(68.9 \%)$, example $(64 \%)$, derivation $(53 \%)$, usage $(45 \%)$, pictorial illustration $(36 \%)$, collocation $(28 \%)$, origin of the words $(38 \%)$, synonyms and antonyms $(47 \%)$. About the look-up habits, the study reported that: 66 students out of 77 reported that they always and sometimes refer to the dictionary to consult the meaning of a word in Arabic, $67 \%$ of the students chose to refer always and sometimes to their dictionary for spellings, $14 \%$ and $24 \%$ of the students chose to always and sometimes check their dictionary for pronunciation, $47 \%$ of the participants reported referring to the dictionary in order to check parts of speech, sometimes, often or always, $29 \%$ stated that they always or sometimes refer to their dictionary to obtain this type of information, $25 \%$ of the students reported that they always or sometimes look up a word for its derivation, $54 \%$ of the students stated that they either rarely or never check their dictionary for countability, 17 students stated that they always/sometimes refer to their dictionary to check verb tense. The study also showed the statistical findings for the difficulties that students encounter when using their dictionaries: pronunciation $(76.6 \%)$, grammatical information $(58 \%)$, selection of the right word (45\%), confirmation of a correct word (39\%), examples (46\%), and definition of words $(27 \%) .86 \%$ of the participants reported that training on dictionary should be integrated into foreign-language classes and $87 \%$ reported that teaching dictionary should be introduced in the curriculum of secondary level.

\section{Research Methodology}

\subsection{Type of Research}

To carry out a descriptive study, a quantitative approach is utilized. Trask (1999) states 'that the quantitative approach has revolutionized the study of language by demonstrating that linguistic behavior is even more highly structured than we have previously suspected'. 


\subsection{Population and Sample of the Study}

230 (138 males and 92 females) learners of the Siraiki language at advanced level ranging from 18 to 24 years of age were purposively selected as the participants of the study. At graduate level, the number of participants was 212 and at masters' level the number of participants was 18 . The participants of the study were selected through purposive sampling technique.

\subsection{Data Collection Tools}

In this study, questionnaire was employed as a research instrument for the collection of data. The lexicographic studies such as Hatherall's (1984), Béjoint's (1989), Iqbal's (1991), Hulstijn and Atkins' (1998), Mackintosh's (1998), Chi's (2003) and Sibtain's (2013) were kept in mind while developing a questionnaire. According to Nesi (2000), research based on questionnaire is perhaps the commonest technique of the investigation of dictionary use. According to Diab (1990), the questionnaire technique will continue to be used as the foremost research instrument for data collection.

\subsection{Research Strategy}

A questionnaire was designed for the learners of the Siraiki language at advanced level to find out the responses of the participants. Questionnaire was written in simple English. Questionnaires were distributed among the students. They were given 45 minutes to answer the questions. Students were asked to contact the researcher present in the classroom in case of any difficulty in understanding the questions.

\subsection{Delimitations of the Study}

The study is limited only to the learners of the Siraiki language at advanced level in Pakistani setting. The study is limited to 230 (138 males and 92 females) participants of Siraiki ranging from 18 to 24 years of age. At graduate level, their number was 212 and at master's level their number was 18. Data were collected through a questionnaire. The purpose of this research was to investigate students' dictionary using habits, their attitudes towards dictionaries, their dictionary needs and problems.

\section{Data Analysis}

In this part, the data collected through questionnaire is analyzed. Data were collected from the leaners of the Siraiki language at advanced level studying in various colleges and universities where Siraiki is being taught in Multan, Bahawalpur and Dear Ghazi Khan divisions. The questionnaire was divided into two sections. Section one deals with personal information. Section two is concerned about students' habits, attitudes towards Siraiki dictionaries, needs and problems. In total the questionnaire has 25 questions.

\subsection{Section One (Personal Information)}

In this section, four questions regarding sex, mother tongue, qualification and level of learning were asked. All the students were of same level, belonging to the same group ranging from 18 to 24 years.

Table 1. Gender of the participants

\begin{tabular}{lll}
\hline Students & Number & Percentage \\
\hline Male & 138 & $60 \%$ \\
Female & 92 & $40 \%$ \\
\hline
\end{tabular}

The study reported that among the respondents, $60 \%(\mathrm{~N}=138)$ were male and $40 \%(\mathrm{~N}=92)$ were female

Table 2. Mother tongue of the participants

\begin{tabular}{lll}
\hline Mother Tongue & Number & Percentage \\
\hline Siraiki & 205 & $89.13 \%$ \\
Punjabi & 25 & $10.86 \%$ \\
\hline
\end{tabular}

When the question on mother tongue was analyzed, the study reported that $89.13 \%(\mathrm{~N}=205)$ respondents speak Siraiki as their mother tongue where as $10.86 \%(\mathrm{~N}=25)$ respondents Punjabi as their mother tongue. 
Table 3. Level of education

\begin{tabular}{lll}
\hline Educational Level & Number & Percentage \\
\hline Graduate & 212 & $92.17 \%$ \\
Master & 18 & $7.82 \%$ \\
\hline
\end{tabular}

Regarding the qualification of the respondents, the study reported that the number of respondents at graduate level was $92.17 \%(\mathrm{~N}=212)$ and at masters' level was $7.82 \%(\mathrm{~N}=18)$.

\subsection{Section Two}

Section two deals with the questions regarding the habits, attitudes, preferences, needs, problems regarding dictionary use of the advanced learners of the Siraiki language.

Table 4. Dictionary ownership

\begin{tabular}{lll}
\hline Dictionary Ownership & Number & Percentage \\
\hline Dictionary Owned & 58 & $25.21 \%$ \\
Dictionary not owned & 172 & $74.98 \%$ \\
\hline
\end{tabular}

Regarding the dictionary ownership, the study reported that $25.21 \%(\mathrm{~N}=58)$ owned Siraiki dictionaries whereas $74.98 \%(\mathrm{~N}=172)$ did not own any Siraiki dictionary.

Table 5. Dictionaries owned by participants

\begin{tabular}{llll}
\hline S. No. & Name of the Dictionary & Number & Percentage \\
\hline 1. & Nisaab Zaroori & 00 & $0 \%$ \\
2. & Glossary of the Agricultural Terms & 00 & $0 \%$ \\
3. & Glossary of the Multani Language & 08 & $13.79 \%$ \\
4. & Grammar and Dictionary of Western Punjabi & 00 & $0 \%$ \\
5. & Dictionary of Jatki or Western Punjbai & 03 & $5.17 \%$ \\
6. & Dar-o-Gauhar & 00 & $0 \%$ \\
7. & Lughaat-e-Siraiki & 06 & $10.34 \%$ \\
8. & Siraiki Sammal & 00 & $0 \%$ \\
9. & Lughaat-e-Dilshadia (Urdu to Siraiki) & 06 & $10.34 \%$ \\
10. & Naveekli Siraiki Urdu Dictionary & 00 & $0 \%$ \\
11. & Lughaat-e-Dilshadia (Siraiki to Urdu) & 00 & $0 \%$ \\
12. & Lughaat-e-Fareedi & 00 & $0 \%$ \\
13. & Chand Siraiki Istalahat wa Mutaradifat & 00 & $0 \%$ \\
14. & Qadeem Siraiki Urdu Lughat & 00 & $0 \%$ \\
15. & Pehli Wadi Siraiki Lughat & 15 & $25.86 \%$ \\
16. & Shaukat-ul-Lughaat & 20 & $34.48 \%$ \\
17. & Poothi & 00 & $0 \%$ \\
\hline
\end{tabular}

Question No. 6 asked the respondents to tick the dictionary they owned. The study reported that $13.79 \%(\mathrm{~N}=8)$ respondents owned Glossary of the Multani Language. Dictionary of Jatki or Western Punjbai is owned by 5.17\% $(\mathrm{N}=3)$ respondents. Lughaat-e-Siraiki and Lughaat-e-Dilshadia (Urdu to Siraiki) were owned by $10.34 \%(\mathrm{~N}=6)$ respondents. Pehli Wadi Siraiki Lughat is owned by $25.86 \%(\mathrm{~N}=15)$. Shaukat-ul-Lughaat is owned by $34.48 \%$ $(\mathrm{N}=20)$.

Table 6. Non-availability of dictionaries

\begin{tabular}{lll}
\hline Statement & Number & Percentage \\
\hline You feel no need of using a dictionary. & 113 & $65.69 \%$ \\
These dictionaries are not available. & 39 & $22.67 \%$ \\
Your teachers do not recommend any of these. & 20 & $11.62 \%$ \\
Any other reason................... & 00 & $0 \%$ \\
\hline
\end{tabular}

The study reported that $74.78 \%(\mathrm{~N}=172)$ respondents did not own dictionary at all. $65.69 \%(\mathrm{~N}=113)$ respondents 
feel no need of using a dictionary, $22.67 \%(\mathrm{~N}=39)$ respondents are of the view that these dictionaries are not easily available and $11.62 \%(\mathrm{~N}=20)$ respondents state that their teachers do not recommend any of these dictionaries.

Table 7. Dictionary consultancy

\begin{tabular}{lll}
\hline Dictionary Consultation & Number & Percentage \\
\hline Library & 156 & $90.69 \%$ \\
Teacher & 12 & $6.97 \%$ \\
Friend & 04 & $2.32 \%$ \\
Don't consult any dictionary & 00 & $0 \%$ \\
\hline
\end{tabular}

The study reported that $90.69 \%(\mathrm{~N}=156)$ respondents use dictionary in libraries, $6.97 \%(\mathrm{~N}=12)$ respondents use dictionaries with their teachers and $2.32 \%(\mathrm{~N}=4)$ respondents reported that use dictionary with their friends.

Table 8. Dictionaries' usefulness in learning a language

\begin{tabular}{lllll}
\hline Responses & Code & Frequency & Percentage & Mean Score \\
\hline Strongly Agree & SA & 85 & 36.96 & \\
Agree & A & 25 & 10.87 & \\
Undecided & U & 100 & 43.48 & 3.73 \\
Disagree & DA & 12 & 5.22 & \\
Strongly Disagree & SDA & 8 & 3.48 & \\
& Total & 230 & 100.00 & \\
\hline
\end{tabular}

Table 8 displays a high frequency of the usefulness of dictionaries in language learning. $47.82 \%$ of respondents agreed with the statement while $8.69 \%$ showed their disagreement with the statement. $43.48 \%$ of the responses were found undecided. Mean score was 3.73 (more than 3) which indicates that the respondents with Siraiki bilingual dictionary favoured the usefulness of dictionary in language learning. Out of 230 respondents, 110 favoured dictionary and further opined on the need of compiling a monolingual dictionary of this language to learn it at the advanced level while 100 respondents showed no interest and left the answer undecided which shows that students of Siraiki language are not well aware about the importance of dictionary use.

Table 9. Non-usefulness of dictionaries in learning the Siraiki language

\begin{tabular}{lllll}
\hline Responses & Code & Frequency & Percentage & Mean Score \\
\hline Strongly Agree & SA & 72 & 31.30 & \\
Agree & A & 11 & 4.78 & \\
Undecided & U & 97 & 42.17 & 3.30 \\
Disagree & DA & 13 & 5.65 & \\
Strongly Disagree & SDA & 37 & 16.09 & \\
& Total & 230 & 100.00 & \\
\hline
\end{tabular}

Table 9 shows a high mean score 3.30 (more than 3) about the role of Siraiki dictionaries in learning and their effectiveness. $36.08 \%$ respondents agreed with the statement while $17.66 \%$ showed their disagreement with the statement. $42.17 \%$ of the responses were found undecided. A high mean score shows that users were less inclined towards using the available dictionaries of Siraiki for learning the language.

Table 10. Semantic information in Siraiki dictionaries

\begin{tabular}{lllll}
\hline Responses & Code & Frequency & Percentage & Mean Score \\
\hline Strongly Agree & SA & 16 & 6.96 & \\
Agree & A & 10 & 4.35 & \\
Undecided & U & 50 & 21.74 & 2.35 \\
Disagree & DA & 116 & 50.43 & \\
Strongly Disagree & SDA & 38 & 16.52 & \\
& Total & 230 & 100.00 & \\
\hline
\end{tabular}


Table 10 shows a low mean score 2.35 (less than 3 ) about the provision of meaning. $11.30 \%$ respondents agreed with the statement while $66.95 \%$ showed their disagreement with the statement. $21.73 \%$ of the responses were found undecided. The respondents use the dictionaries of the Siraiki language for looking up meaning but the dictionaries are found deficient in this respect. The lexicographers select the lexical items according to their own intuition and give the definition according to their own knowledge and perception. Equivalents are given in the dictionary, their definitions are not provided with the dictionary.

Table 11. Lack of reference skills

\begin{tabular}{lllll}
\hline Responses & Code & Frequency & Percentage & Mean Score \\
\hline Strongly Agree & SA & 14 & 6.09 & \\
Agree & A & 11 & 4.78 & \\
Undecided & U & 65 & 28.26 & 2.29 \\
Disagree & DA & 78 & 33.91 & \\
Strongly Disagree & SDA & 62 & 26.96 & \\
& Total & 230 & 100.00 & \\
\hline
\end{tabular}

Table 11 shows a low mean score 2.29 (less than 3) about the potential of the students about dictionary use. 10.87\% respondents agreed with the statement while $60.87 \%$ showed their disagreement with the statement. $28.26 \%$ of the responses were found undecided. The low mean score reveals the fact that the respondents are not able to benefit from the dictionaries due to lack of reference skills in dictionary use.

Table 12. Dictionary use - a time-consuming task

\begin{tabular}{lllll}
\hline Responses & Code & Frequency & Percentage & Mean Score \\
\hline Strongly Agree & SA & 39 & 16.96 & \\
Agree & A & 31 & 13.48 & \\
Undecided & U & 140 & 60.87 & 3.36 \\
Disagree & DA & 13 & 5.65 & \\
Strongly Disagree & SDA & 7 & 3.04 & \\
& Total & 230 & 100.00 & \\
\hline
\end{tabular}

Table 12 shows a high mean score 3.36 (more than 3) about the consumption of time in dictionary. $30.43 \%$ respondents agreed with the statement while $8.69 \%$ showed their disagreement with the statement. $60.87 \%$ of the responses were found undecided. 70 respondents out of 230 responded that dictionary-use is a time-consuming task.

Table 13. Provision of different senses in the dictionary

\begin{tabular}{lllll}
\hline Responses & Code & Frequency & Percentage & Mean Score \\
\hline Strongly Agree & SA & 18 & 7.83 & \\
Agree & A & 7 & 3.04 & \\
Undecided & U & 65 & 28.26 & 2.16 \\
Disagree & DA & 43 & 18.70 & \\
Strongly Disagree & SDA & 97 & 42.17 & \\
& Total & 230 & 100.00 & \\
\hline
\end{tabular}

Table 13 shows a low mean score 2.16 (less than 3) about the provision of senses in Siraiki dictionaries. 10.87\% respondents agreed with the statement while $60.87 \%$ showed their disagreement with the statement. $28.26 \%$ of the responses were found undecided. The respondents use the dictionary for learning about different senses of words, but the dictionaries are deficient in fulfilling this need. Equivalents are given in the dictionary, their different shades of meaning (senses) are not provided with the dictionary. 
Table 14. Alphabetical order in dictionaries

\begin{tabular}{lllll}
\hline Responses & Code & Frequency & Percentage & Mean Score \\
\hline Strongly Agree & SA & 40 & 17.39 & \\
Agree & A & 60 & 26.09 & \\
Undecided & U & 101 & 43.91 & 3.40 \\
Disagree & DA & 10 & 4.35 & \\
Strongly Disagree & SDA & 19 & 8.26 & \\
& & 230 & 100.00 & \\
\hline
\end{tabular}

Table 14 shows a high mean score 3.40 (more than 3) about the order of lexical items in Siraiki dictionaries. $43-$ $48 \%$ respondents agreed with the statement while $12.61 \%$ showed their disagreement with the statement. $43.91 \%$ of the responses were found undecided. The high mean score reveals the fact that these dictionaries offer entries in alphabetical order and this is a positive aspect of Siraiki dictionaries.

Table 15. Provision of canonical form

\begin{tabular}{lllll}
\hline Responses & Code & Frequency & Percentage & Mean Score \\
\hline Strongly Agree & SA & 6 & 2.61 & \\
Agree & A & 4 & 1.74 & \\
Undecided & U & 100 & 43.48 & 2.15 \\
Disagree & DA & 28 & 12.17 & \\
Strongly Disagree & SDA & 92 & 40.00 & \\
& Total & 230 & 100.00 & \\
\hline
\end{tabular}

Table 15 shows a low mean score 2.15 (less than 3) about the provision of senses in Siraiki dictionaries. 4.35\% respondents agreed with the statement while $52.17 \%$ showed their disagreement with the statement. $43.48 \%$ of the responses were found undecided. A low mean score revealed the fact that Siraiki dictionaries are found deficient in matter of the format of headword or lemma in canonical form.

Table 16. Provision of information on collocation

\begin{tabular}{lllll}
\hline Responses & Code & Frequency & Percentage & Mean Score \\
\hline Strongly Agree & SA & 4 & 1.74 & \\
Agree & A & 1 & 0.43 & \\
Undecided & U & 183 & 79.57 & 2.72 \\
Disagree & DA & 11 & 4.78 & \\
Strongly Disagree & SDA & 31 & 13.48 & \\
& Total & 230 & 100.00 & \\
\hline
\end{tabular}

Table 16 shows a low mean score 2.72 (less than 3) about the provision of collocation in Siraiki dictionaries. 2.17\% respondents agreed with the statement while $18.26 \%$ showed their disagreement with the statement. $79.57 \%$ of the responses were found undecided. A very low mean score reveals the fact that Siraiki dictionaries are found deficient about the provision of collocation and this is another reflection on the dictionaries. Siraiki dictionaries are deficient in the provision of the possible co-occurrence of words.

Table 17. Provision of definition in Siraiki dictionaries

\begin{tabular}{lllll}
\hline Responses & Code & Frequency & Percentage & Mean Score \\
\hline Strongly Agree & SA & 11 & 4.78 & \\
Agree & A & 4 & 1.74 & \\
Undecided & U & 118 & 51.30 & 2.37 \\
Disagree & DA & 22 & 9.57 & \\
Strongly Disagree & SDA & 75 & 32.61 & \\
& Total & 230 & 100.00 & \\
\hline
\end{tabular}


Table 17 shows a low mean score 2.37 (less than 3) in matter of dictionary look-ups for definition. $6.52 \%$ respondents agreed with the statement while $42.17 \%$ showed their disagreement with the statement. $51.30 \%$ of the responses were found undecided. Only 15 respondents out of 230 showed their interest to consult a dictionary in matter of definition. This shows that either Siraiki learners are not well informed about the use of dictionary or Siraiki dictionaries do not meet their requirements in this regard.

Table 18. Looking up the following information in the dictionary

\begin{tabular}{lllllllllll}
\hline Information & $\mathbf{1}$ & & $\mathbf{2}$ & & $\mathbf{3}$ & & $\mathbf{4}$ & & $\mathbf{5}$ \\
Category & $\mathbf{N}$ & $\mathbf{P}$ & $\mathbf{N}$ & $\mathbf{P}$ & $\mathbf{N}$ & $\mathbf{P}$ & $\mathbf{N}$ & $\mathbf{P}$ & $\mathbf{N}$ & $\mathbf{P}$ \\
\hline Pronunciation & 00 & $0 \%$ & 29 & $12.60 \%$ & 156 & $67.82 \%$ & 45 & $19.56 \%$ & 00 & $0 \%$ \\
Spelling & 6 & $2.60 \%$ & 14 & $6.08 \%$ & 131 & $56.95 \%$ & 79 & $34.34 \%$ & 00 & $0 \%$ \\
Meaning & 198 & $86.08 \%$ & 20 & $8.69 \%$ & 12 & $5.21 \%$ & 00 & $0 \%$ & 00 & $0 \%$ \\
Grammar & 16 & $6.95 \%$ & 46 & $20 \%$ & 72 & $31.30 \%$ & 96 & $41.73 \%$ & 00 & $0 \%$ \\
Examples & 00 & $0 \%$ & 00 & $0 \%$ & 67 & $29.13 \%$ & 83 & $36.08 \%$ & 80 & $34.78 \%$ \\
Notes on usage & 00 & $0 \%$ & 26 & $11.30 \%$ & 84 & $36.52 \%$ & 53 & $23.04 \%$ & 67 & $29.13 \%$ \\
\hline
\end{tabular}

Note. $\mathrm{N}=$ Number and $\mathrm{P}=$ Percentage; 1-All the time; 2-Very often; 3-Quite often; 4-Occasionally; 5-Never.

Table 18 shows that for pronunciation $12.60 \%(\mathrm{~N}=29)$ respondents reported very often, $67.82 \%(\mathrm{~N}=156)$ respondents reported quite often and $19.56 \%(\mathrm{~N}=45)$ respondents reported occasionally. For spelling $2.60 \%$ $(\mathrm{N}=6)$ respondents reported all the time, 6.08\% $(\mathrm{N}=14)$ respondents reported very often, $56.95 \%(\mathrm{~N}=131)$ respondents reported quite often and $34.34 \%(\mathrm{~N}=79)$ reported occasionally. For meaning $86.08 \%(\mathrm{~N}=198)$ respondents reported all the time, $8.69 \%(\mathrm{~N}=20)$ respondents reported very often and $5.21 \%(\mathrm{~N}=12)$ respondents reported quite often. For grammar 6.95\% ( $\mathrm{N}=16)$ respondents reported all the time, 20\% $(\mathrm{N}=46)$ respondents reported very often, $31.30 \%(\mathrm{~N}=72)$ respondents reported quite often and $41.73 \%(\mathrm{~N}=96)$ reported occasionally. For examples $29.13 \%(\mathrm{~N}=67)$ respondents reported quite often, $36.08 \%(\mathrm{~N}=83)$ respondents reported occasionally and $34.78 \%(\mathrm{~N}=80)$ respondents reported never. For notes on usage $11.30 \%(\mathrm{~N}=26)$ respondents reported very often, $36.52 \%(\mathrm{~N}=84)$ respondents reported quite often, $23.04 \%(\mathrm{~N}=53)$ respondents reported occasionally and $29.13 \%(\mathrm{~N}=67)$ respondents reported never.

Table 19. Problems while using dictionaries (tick more than one if you wish)

\begin{tabular}{lll}
\hline Statement & Number & Percentage \\
\hline Problem in understanding dictionary symbols & 196 & $85.21 \%$ \\
Problems in looking up meanings of words & 183 & $79.56 \%$ \\
Problem in pronouncing words & 96 & $41.73 \%$ \\
Problem in understanding grammatical information & 115 & $50 \%$ \\
Problem in looking up synonyms/antonyms & 103 & $44.78 \%$ \\
Problem in looking up idioms and phrases & 149 & $64.78 \%$ \\
Any other (please specify) & 00 & $0 \%$ \\
\hline
\end{tabular}

Question no 20 asked the respondents about the problem which they faced while using dictionaries. Table 19 shows the results in terms of value and percentage.

\section{Q. No. 21 Have you ever been taught dictionary use in classroom?}

\section{Q. No. 22 Will you attend workshops on teaching dictionary use?}

Question no 21 asked the respondents whether they had been taught dictionary use in classroom. All the respondents gave their answers in negative and when question no 22 asked the respondents whether they would attend workshops on teaching dictionary use, all the respondents gave their answers in positive.

\section{Conclusion, Findings, Recommendations and Suggestions}

The present study was carried out to explore the habits, attitudes, preferences and problems of the learners of the Siraiki language at advanced level towards Siraiki dictionaries in Pakistan. Data were collected through a questionnaire containing 22 items. Different kinds of questions relating to their habits, attitudes, preferences and problems were asked in the questionnaire. Findings of the study are as under: 


\section{Q. No. 1 For what specific purposes do learners of Siraiki at advanced level consult a dictionary?}

In this regard, certain questions were asked to the respondents. Their responses showed that only $25.21 \%$ of the respondents owned Siraiki dictionaries. $47.82 \%$ of the respondents fovoured the statement that dictionaries were useful in helping learners to learn a language and they opined on the need of compiling a monolingual dictionary of the Siraiki language. $10.43 \%$ of the respondents agreed that Siraiki dictionaries provide meanings. Respondents reported that they use dictionaries for meaning but the dictionaries are deficient in fulfilling this need and the respondents are not able to benefit from the dictionaries because of lack of reference skills and lack of training in dictionary use. Regarding the question about the consumption of time in dictionary use, a high mean score 3.36 (more than 3) shows that dictionary use is a time-consuming task. About the provision of senses in Siraiki dictionaries, $60.87 \%$ of the respondents did not agree with the statement. The respondents reported that Siraiki dictionaries were deficient in matter of senses. Regarding the alphabetical order of the lexical items, the study shows a high mean score i.e., 3.40 (more than 3), it means that Siraiki dictionaries provide entries in alphabetical order. Regarding the canonical form, provision of collocation and provision of definition, the study shows very low mean score: canonical form 2.15 (less than 3), collocation 2.72 (less than 3 ) and definition 2.37 (less than 3).

\section{Q. No. 2 What lexical knowledge do they look-up most?}

Learners of the Siraiki language at advanced level use dictionaries for meaning, pronunciation, spelling, grammar, examples and notes on usage. Table 17 shows the correct value and percentage in detail.

Q. No. 3 What problems do Siraiki learners at advanced level encounter while consulting dictionary?

Regarding the problems that the participants faced while using Siraiki dictionaries, the study reported that majority of the students $(85.21 \%)$ faced problems in understanding dictionary symbols. $79.56 \%$ of the participants faced difficulties in finding the proper meanings of the words. $41.73 \%$ of the participants faced difficulties in pronouncing words. $50 \%$ of the participants faced difficulties in understanding grammatical information. $44.78 \%$ of the participants faced difficulties in looking up synonyms/antonyms. $64.78 \%$ of the participants faced difficulties in looking up idioms and phrases.

\section{Q. No. 4 How can adequate training in dictionary use help them improve their reference skills?}

The study reported that due to absence of training in dictionary use, the respondents were found reluctant towards dictionary use. When the respondents were asked whether they had been taught dictionary use in classroom, all the respondents gave their answers in negative and when they asked whether they would attend workshops on teaching dictionary use, all the respondents gave their answers in positive.

\section{References}

Al-harbi, B. I. (2012). An Investigation into Dictionary Use by Saudi Tertiary EFL Students. Unpublished PhD Dissertation. University of Exeter.

Ashraf, A. (2010). Design features of monolingual Urdu pedagogical dictionary for advanced learners of Urdu. Unpublished PhD Dissertation. Multan: Bahauddin Zakariya University.

Atkins, B. T. S., \& Varantola, K. (1998). Language learners using dictionaries: The final report on the EURALEX/AILA research project on dictionary use. In B. T. S. Atkins (Ed.), Studies of Dictionary Use by Language Learners and Translators (pp. 21-81). https://doi.org/10.1515/9783110929997.21

Béjoint, H. (1981). The foreign student's use of monolingual English dictionaries: a study of language needs and reference skills. Applied Linguistics, 2(3), 207-222. https://doi.org/10.1093/applin/2.3.207

Béjoint, H. (1999). Compound nouns in learners' dictionaries. In T. Herbst \& K. Popp (Eds.), The Perfect Learners' Dictionary (?) Max Niemeyer: Verlag. https://doi.org/10.1515/9783110947021.81

Campoy-Cubbilo, M. C. (2002). Dictionary use and dictionary needs of ESP students: An experimental approach. International Journal of Lexicography, 15(3), 206-228. https://doi.org/10.1093/ijl/15.3.206

Chi, A. (2003). An empirical study of the efficacy of integrating the teaching of dictionary use into a tertiary English curriculum in Hong Kong. A PhD thesis, published in research reports Vol. 4 Language Center Hong Kong, Hong Kong: University of Science and Technology.

Cowie, A. P. (1999). English Dictionaries for Foreign Learners. Oxford: Clarendon Press.

Diab, T. (1990). Pedagogical lexicography. Tübingen: Max Niemeyer Verlag. https://doi.org/10.1515/9783111347783 
Hartmann, R. R. K. (1983). The bilingual leaner's dictionary and its uses. Multilingua, 2(4), 195-201. https://doi.org/10.1515/mult.1983.2.4.195

Hartmann, R. R. K. (1999). Case Study: The Exeter University Survey of Dictionary Use. In R. R. K. Hartmann (Ed.), Thematic Network Project in the area of Languages Subproject 9: Dictionaries. Dictionaries in Language Learning. Berlin: Freie Universität.

Haseeb, A. (2007). A Study of Dictionary Using Habits of Students at Secondary Level in the English Medium Schools in Multan. Unpublished M. Phil Thesis, Multan: Bahauddin Zakariya University.

Hatherall, G. (1984). Studying dictionary use: some findings and proposals. In R. Hartmann (Ed.), Papers from the International Conference on Lexicography at Exeter, 9-12 September 1983 (pp. 182-189). https://doi.org/10.1515/9783111593166-025

Iqbal, Z. (1991). Pedagogical dictionaries and the learner's reference skills. Pakistan Journal of Language, 1(1), $45-65$.

Iqbal, Z. (1992). Lexical problems in L2 learning. Pakistan Journal of Language, 2(1), 47-60.

Lew, R. (2004). Which dictionary for whom? Receptive use of bilingual monolingual and semi-bilingual dictionaries by Polish learners of English. Poznan: Motivex. Retrieved from http://hdl.handle.net/10593/655

Li, L. (1998). A study of dictionary use by Chinese university learners of English for specific purposes. Ph.D. thesis. University of Exeter.

Mackintosh, K. (1995). An empirical study of dictionary use of version. M.A. Thesis. University of Ottawa.

Marjeta (2004). Language learners and their use of dictionaries: The case of Slovenia. Retrieved from http://webdoc.sub.gwdg.de/edoc/ia/eese/artic24/marjeta/3_2004.html

Momoi, H. (1998). ESL learners' behavior in using bilingual dictionaries while writing an English composition. Unpublished M. Ed. Dissertation. Tokyo: Tokyo Gakugei University.

Nesi, H. (1999). A user's guide to electronic dictionaries for language learners. International Journal of Lexicography, 12(1), 55-66. https://doi.org/10.1093/ijl/12.1.55

Nesi, H. (2000). The Use and Abuse of EFL Dictionaries. Tübingen: Max Niemeyer Verlag. https://doi.org/10.1515/9783110946031

Papanikolaou, E. (2003). Dictionary use in a reading task among Greek junior secondary school students of English: A multi-method approach. $\mathrm{PhD}$ thesis. University of Exeter.

Ramos (2005). Research on dictionary use by trainee translators. Translation Journal, 9(2).

Ryu, J. (2006). Dictionary Use by Korean EFL College Students. Language and Information Society, 7, 83-114.

Sibtain, M. (2011). A description of some aspects of lexicography in the Punjabi language in Pakistan. Unpublished PhD Dissertation. Multan: Bahauddin Zakariya University.

Tang, G. M. (1997). Pocket electronic dictionaries for second language learning: help or hindrance? TESL Canada Journal, 15(1), 39-57. https://doi.org/10.18806/tesl.v15i1.691

Tono, Y. (2001). Research on Dictionary Use in the Context of Foreign Language Learning. Tubingen: Max Neimeyer Verlag. https://doi.org/10.1515/9783110915013.15

Zgusta. L. (1971) Manual of Lexicography. The Hague: Mouton. https://doi.org/10.1515/9783111349183.358

\section{Appendix A}

\section{Questionnaire for the Learners}

Dear respondent! This questionnaire is a part of $\mathrm{PhD}$ studies on the functionality of the existing Siraiki dictionaries. You are requested to kindly provide your responses honestly. All information gathered through this questionnaire will contribute to promote the lexicographic practice in this part of the world. You are welcome to give your comments in Siraiki, Urdu or any language you may opt.

\section{Please tick $(\checkmark)$ the relevant}

\section{(Section-A)}

Q1) Gender: (a) Male (b) Female 
Q2) Mother tongue: Urdu / Siraiki / Punjabi /English / other
Q3) Qualification:
(a) Undergraduate
(b) Graduate
(c) Masters

Q4) Level of learning:

(a) College level

(b) University level

\section{(Section-B)}

Q5) Do you own any dictionary of Siraiki? Yes/No

Q6) If answer to Q5 is 'Yes', which Siraiki dictionary do you use?

\begin{tabular}{ll}
\hline S. No. & Name of the Dictionary \\
\hline 1. & Nisaab Zaroori \\
2. & Glossary of the Agricultural Terms $(\checkmark)$ \\
3. & Glossary of the Multani Language \\
4. & Grammar and Dictionary of Western Punjabi \\
5. & Dictionary of Jatki or Western Punjbai \\
6. & Dar-o-Gauhar \\
7. & Lughaat-e-Siraiki \\
8. & Siraiki Sammal \\
9. & Lughaat-e-Dilshadia (Urdu to Siraiki) \\
10. & Naveekli Siraiki Urdu Dictionary \\
11. & Lughaat-e-Dilshadia (Siraiki to Urdu) \\
12. & Lughaat-e-Fareedi \\
13. & Chand Siraiki Istalahat wa Mutaradifat \\
14. & Qadeem Siraiki Urdu Lughat \\
15. & Pehli Wadi Siraiki Lughat \\
16. & Shaukat-ul-Lughaat \\
17. & Poothi \\
\hline
\end{tabular}

Q7) If answer to Q5 is' No' then why don't you own a dictionary?
a. You feel no need of using a dictionary.
b. These dictionaries are not available.
c. Your teachers do not recommend any of these
d. Any other reason

Q8) If your answer to Q05 is 'No', where do you consult dictionary/dictionaries from?
a. Library
b. Teacher
c. Friend
d. Don't Consult any dictionary

Q9) Dictionaries are useful in helping students to learn a language. a-Strongly agree b-Agree c-Disagree d-Strongly disagree e-I don't know Q10) Dictionaries are not useful in helping me to learn Siraiki. a-Strongly agree b-Agree c-Disagree d-Strongly disagree e-I don't know Q11) Siraiki Dictionaries provide the meaning of the word we look up. a-Strongly agree b-Agree c-Disagree d-Strongly disagree e-I don't know

Q12) Siraiki Dictionaries are not helpful because many students do not know how to use their potential. a-Strongly agree b-Agree c-Disagree d-Strongly disagree e-I don't know Q13) Using Siraiki dictionaries is a time-consuming task. a-Strongly agree b-Agree c-Disagree d-Strongly disagree e-I don't know Q14) You often use a Siraiki dictionary for knowing different senses of a word. a-Strongly agree b-Agree c-Disagree d-Strongly disagree e-I don't know 
Q15) The bilingual dictionary of Siraiki you use gives words in alphabetical order.

$$
\text { a-Strongly agree b-Agree c-Disagree d-Strongly disagree e-I don't know }
$$

Q16) The bilingual dictionary of Siraiki you use gives entries in canonical form.

$$
\text { a-Strongly agree b-Agree c-Disagree d-Strongly disagree e-I don't know }
$$

Q17) Siraiki dictionary you use provides information on collocation.

$$
\text { a-Strongly agree b-Agree c-Disagree d-Strongly disagree e-I don't know }
$$

Q18) You look up a dictionary of Siraiki for definition.

$$
\text { a-Strongly agree b-Agree c-Disagree d-Strongly disagree e-I don't know }
$$

Q19) How often do you look up the following information in your dictionary?

\begin{tabular}{llllll}
\hline Information Category & $\mathbf{1}$ & $\mathbf{2}$ & $\mathbf{3}$ & $\mathbf{4}$ & $\mathbf{5}$ \\
\hline Pronunciation & & & & & \\
Spelling & & & & & \\
Meaning & & & & & \\
Grammar & & & & & \\
Examples & & & & \\
Notes on usage & & & & \\
\hline
\end{tabular}

Note. 1-All the time; 2-Very often; 3-Quite often; 4-Occasionally; 5-Never.

Q20) What are the problems, which you face while using dictionaries? (Tick more than one if you wish)
a. Problem in understanding dictionary symbols
b. Problems in looking up meanings of words
c. Problem in pronouncing words
d. Problem in understanding grammatical information
e. Problem in looking up synonyms/antonyms
f. Problem in looking up idioms and phrases
g. Any other (please specify)

Q21) Have you ever been taught dictionary use in classroom?

Q22) Will you attend workshops on teaching dictionary use?

$$
\begin{aligned}
& \text { Yes/No } \\
& \text { Yes/No }
\end{aligned}
$$

\section{Thanks}

\section{Copyrights}

Copyright for this article is retained by the author, with first publication rights granted to the journal.

This is an open-access article distributed under the terms and conditions of the Creative Commons Attribution license (http://creativecommons.org/licenses/by/4.0/). 